\title{
REMOVAL OF CRYSTAL VIOLET DYE FROM AQUEOUS SOLUTION BY GAMMA IRRADIATION
}

\author{
FAIZA REHMAN ${ }^{\prime}$, MURTAZA SAYED ${ }^{\prime *}$, JAVED ALI KHAN ${ }^{1}$, HASAN M. KHAN ${ }^{1 *}$ \\ ${ }^{1}$ Radiation and Environmental Chemistry Laboratory, National Centre of Excellence in Physical Chemistry, \\ University of Peshawar, 25120, Pakistan \\ ${ }^{2}$ National Centre of Excellence in Physical Chemistry, University of Peshawar, 25120, Pakistan
}

\begin{abstract}
In this study the radiation-induced degradation of crystal violet $(\mathrm{CV})$ dye under various experimental conditions has been investigated. $\mathrm{D}_{0.5}, \mathrm{D}_{0.9}$ and $\mathrm{D}_{0.99}$ values suggests that lower doses are required for $50 \%, 90 \%$ and $99 \%$ removal of $\mathrm{CV}$ dye when the sample solution contains excessive amount of ${ }^{\circ} \mathrm{OH}$ radicals. The removal efficiency of $\mathrm{CV}$ dye in terms of G-values was also calculated under each reaction conditions. The results showed that ${ }^{\circ} \mathrm{OH}$ radicals are playing effective role in the degradation of $\mathrm{CV}$ dye as compared to $\mathrm{e}_{\text {aq }}{ }^{-}$and ${ }^{\circ} \mathrm{H}$ radicals. The gamma irradiation process effectively degraded $\mathrm{CV}$ dye at all $\mathrm{pH}$ values. The organic byproducts were examined and accordingly degradation pathway was proposed.
\end{abstract}

Keywords: Crystal violet dye, gamma irradiation, ${ }^{\circ} \mathrm{OH}-$ radicals, removal efficiency.

\section{INTRODUCTION}

Water pollution have gained lot of attention worldwide because wastewaters from various industrial sectors cause serious environmental and health problems. The wastewater from textile industry containing even very low concentration of dyes can cause waste streams to become intensely colored. Besides from their negative visual effects, these compounds are highly non biodegradable and mostly carcinogenic and mutagenic in nature [1].

In textile industry synthetic dyes are used as colouring material. It is estimated that annually about 1 million tons of these dyes are produced, of which 50,000 tons are lost in effluents during application and manufacturing, $5-15 \%$ of which are directly released into the environment without any adequate treatment [2]. The organic groups present in dyes results in mortality, genotoxicity, mutagenicity and carcinogenicity, so it is necessary to remove these organic pollutants from wastewaters before discharge to major water bodies (e.g., lakes, rivers or oceans). Different processes which are involve in textile production like dyeing and washing results in the production of large quantities of wastewater along with different toxic chemicals [3].

In textile industry, a major class of commercial dyes is crystal violet (CV), which is used for different purposes, such as for dermatological agent, veterinary medicine, biological staining, additive in poultry feed to reduce spread of fungus, mold and intestinal parasites and for textile dying and paper printing. However, due to poor treatment techniques for the purification of $\mathrm{CV}$ containing wastewater from industries it is frequently detected in surface water [4]. This dye is cationic in nature and is more toxic than anionic dye as it can easily interact with negatively charged membrane surfaces and can enter into cells and concentrate in cytoplasm [5].

Several techniques have been applied for the removal of $\mathrm{CV}$ from wastewater which includes physical, chemical and biological techniques [6]. Conventional methods include wet air oxidation, catalytic processes, biochemical processes, biological processes and physical adsorption for the removal of dyes from aquatic environment. Biological treatment is not a complete solution to the wastewater pollution problem because majority of dyes are non biodegradable [7]. However, a new treatment technology called Advanced Oxidation Processes (AOPs), like Fenton, electro-Fenton and photoFenton processes, and combinations of $\mathrm{O}_{3}\left(\right.$ or $\mathrm{H}_{2} \mathrm{O}_{2}$ ) with UV radiation and/ or $\mathrm{TiO}_{2}$, among others, are very effective for the treatment and elimination of textile dyes from water [8]. These processes in a very short reaction time are capable to completely decolorize and partially mineralize the textile industry dyes. AOPs involve the production of ${ }^{\circ} \mathrm{OH}$ radical, a powerful and non-selective oxidant that can be degrade almost all organic pollutants [9].

Gamma irradiation technology, as an advanced oxidation process, has been recognized as a promising process for hazardous organic wastewater treatment. It is well known that most colored materials undergo bleaching or color changes when exposed to ionizing radiation. Therefore, gamma and electron beam irradiation can be considered as methods for the treatment of wastewater from textile industries. Extensive research work has been carried out in literature on the radiation-induced decoloration and degradation of aqueous solutions of dyes [10].

\section{MATERIALS AND METHODS}

\subsection{Chemicals}

$\mathrm{CV}$ was obtained from sigma aldrich. The chemical structure of CV dye is presented in the inset of Fig. 1. iso - propanol, tert - butanol and sulphuric acid were taken from BDH. Ferrous sulphate heptahydrate was obtained from Scharlau. Sodium Chloride and potassium dichromate used in this work were of Merck. All chemicals were of analytical reagent grade and used as received without further purification. Milli-Q (resistivity $\geq 18.2 \mathrm{M} \Omega \mathrm{cm}$ ) water was used during preparation of all CV samples. Nitrogen and nitrous oxide gasses used in the present study were of at least $99.999 \%$ purity.

\subsection{Irradiation experiments}

$\mathrm{CV}$ containing aqueous sample solutions were placed into $15 \mathrm{~mL}$ pyrex glass tubes and irradiated with a ${ }^{60} \mathrm{Co}$ gamma-irradiation source (National Institute for Food and Agriculture, Peshawar) with dose rate of $294 \mathrm{~Gy} / \mathrm{min}$. The dose rate was calculated by Frickie dosimetry [11]. All the experiments were performed at natural $\mathrm{pH}$ of the sample solution $(\mathrm{pH}=5.8)$ in triplicate.

\subsection{Analyses of gamma-irradiated samples}

The CV samples obtained after gamma irradiation procedures were then analyzed by double beam UV-Visible spectrophotometer (Perkin Elmer, Lambda 650). The UV-Visible spectrophotometer was calibrated for absorbance scale by $\mathrm{K}_{2} \mathrm{Cr}_{2} \mathrm{O}_{7}$ and wavelength scale by holmium oxide filter in the wavelength range of $260-800 \mathrm{~nm}$. The UV-absorption spectrum of 3.5 $\times 10^{-5} \mathrm{M} \mathrm{CV}$ dye gives strong absorption peak at $588 \mathrm{~nm}$ as shown in Fig.1.

\subsection{Calculation of dose constant}

The removal of $\mathrm{CV}$ dye by gamma irradiation can usually be expressed by equation 1 [12]. The dose constant, $k$, is the slope of natural logarithm (ln) of the compound concentration versus absorbed dose.

$$
\ln \left(\mathrm{C} / \mathrm{C}_{0}\right)=-k \mathrm{D}
$$

where $C$ is the concentration after gamma irradiation (M), $C$ the initial concentration (M), $k$ the dose constant $\left(\mathrm{Gy}^{-1}\right)$ and $\mathrm{D}$ is the absorbed dose (Gy).

Dose constants were used to calculate the absorbed doses required for $50 \%$, $90 \%$ and $99 \%$ degradation of $\mathrm{CV}\left(\mathrm{D}_{0.5, \mathrm{D} 0.9 \text { and Do.99 }}\right.$ values) by using equations (3), (4) and (5), respectively [12].

$$
\begin{aligned}
& \mathrm{D}_{0.5}=(\ln 2) / \mathrm{k} \\
& \mathrm{D}_{0.9}=\ln (10) / \mathrm{k} \\
& \mathrm{D}_{0.99}=\ln (100) / \mathrm{k}
\end{aligned}
$$

\subsection{Calculation of G-Value}

$\mathrm{G}$ value is defined as the number of molecules formed or destroyed by absorbing $100 \mathrm{eV}$ of energy [13]. The degradation efficiency of pollutant removal can be described by G-value during ionizing radiation calculated by equation (5) [14].

$\mathrm{G}=6.023 \times 10^{23} \Delta \mathrm{R} / 6.24 \times 10^{16} \mathrm{D}$ 
where $\Delta R$ is defined as change in concentration of the $C V(M)$; $D$ is the absorbed dose (Gy); $6.24 \times 10^{16}$ is the conversion factor from "Gy" to " $100 \mathrm{eV} / \mathrm{L}$ "; and $6.023 \times 10^{23}$ is the Avogadro's constant.

2.6. Probability calculations for the determination of concentration of added scavenger

Competition kinetics was applied to determine the concentration of added scavenger (tert-BUOH/ iso-PrOH) that can effectively compete with $\mathrm{CV}$ dye for ${ }^{\circ} \mathrm{OH}$ radicals.

When water sample is gamma - irradiated ${ }^{\circ} \mathrm{OH}$ radicals are produced that rapidly reacts with the $\mathrm{CV}$ dye and added scavenger (tert-BUOH or iso $-\mathrm{PrOH}$ in the present case) at rate constants $K_{1}$ and $K_{2}$, respectively.

$$
\begin{aligned}
& \cdot \mathrm{OH}+\mathrm{CV} \stackrel{k_{1}}{\longrightarrow} \text { Products } \\
& \cdot \mathrm{OH}+\text { tert-BUOH } / \text { iso }- \text { PrOH } \stackrel{k_{2}}{\longrightarrow} \text { Products }
\end{aligned}
$$

The probability that the added scavenger effectively scavenges the amount of $\mathrm{OH}$ radicals from aqueous solution can be represented by equation (6) [15].

$$
P_{(\cdot \mathrm{OH} \rightarrow \text { tert }-\mathrm{BUOH} / \text { iso }-\mathrm{Pr} \mathrm{OH})}=\frac{\left.k_{1} \bullet^{\circ} \mathrm{OH}\right][\text { tert- } \mathrm{BUOH} / \text { iso }-\mathrm{PrOH}]}{k_{1}\left[{ }^{\bullet} \mathrm{OH}\right][\text { tert }-\mathrm{BUOH} / \text { iso }-\mathrm{PrOH}]+\mathrm{k}_{2}\left[{ }^{\bullet} \mathrm{OH}\right][\mathrm{CV}]}
$$

OR,

$$
P_{\left({ }^{\circ} \mathrm{OH} \rightarrow \text { tert }-\mathrm{BUOH} / \text { iso }-\mathrm{Pr} \mathrm{OH}\right)}=\frac{k_{1}[\text { tert }-\mathrm{BUOH} / \text { iso }-\mathrm{PrOH}]}{k_{1}[\text { tert }-\mathrm{BUOH} / \text { iso }-\mathrm{PrOH}]+\mathrm{k}_{2}[\mathrm{CV}]}
$$

Substituting the values of $k_{1}$ as $8 \times 10^{9} \mathrm{M}^{-1} \mathrm{~s}^{-1}[16], k_{2}$ as $5.5 \times 10^{8} \mathrm{M}^{-1} \mathrm{~s}$ ${ }^{1}$ (using tert-BUOH as scavenger) or $6.3 \times 10^{8} \mathrm{M}^{-1} \mathrm{~s}^{-1}$ (using iso-PrOH as scavenger) [17] and concentration of $\mathrm{CV}$ dye as $3.5 \times 10^{-5} \mathrm{M}$. The concentration of added tert-BUOH or iso-PrOH was found to be $10^{-2} \mathrm{M}$ that scavenges nearly $90 \%$ of ${ }^{\circ} \mathrm{OH}$ from $\mathrm{CV}$ dye containing aqueous solution.

\section{RESULTS AND DISCUSSION}

During water radiolysis following type of major reactive species, shown in equation (8) are produced. These species then attack the target pollutant and causes its degradation [18].

$\gamma$-ray

$\mathrm{H}_{2} \mathrm{O} \ldots . . \wedge . . \wedge^{\prime} \ldots>\mathrm{e}^{-}{ }_{\text {aq }}(2.6),{ }^{\circ} \mathrm{H}(0.55), \cdot \mathrm{OH}(2.7), \mathrm{H}_{2}(0.45), \mathrm{H}_{2} \mathrm{O}_{2}(0.71), \mathrm{H}_{3} \mathrm{O}^{+}(2.6)$ $(8)$

The number in parenthesis indicates the G-values in molecules / $100 \mathrm{eV}$ corresponding to each species. Among these species the main radicals are $\mathrm{e}^{-},{ }^{-} \mathrm{OH}$ and ${ }^{\circ} \mathrm{H}$. The most interesting advantage of the gamma irradiation process is that it simultaneously generates oxidizing specie such as ${ }^{\circ} \mathrm{OH}$ radical and reducing specie such as $\mathrm{e}^{-}$in a same system. In a $\mathrm{pH}$ range of 3 11, radiolysis of air-free water leads to the formation of a suite of radical species. Hydroxyl radicals preferentially attack the aromatic ring because of their electrophilicity to form hydroxyl-adducted products or ring-opened products. On the other hand, hydrated electrons and hydrogen atoms have less reactivity to the aromatic ring but demonstrate particularly sensitive to well halogenated organic compounds and heavy metals in wastewater [19].

\subsection{Reaction of $\mathrm{CV}$ dye with ' $\mathrm{OH}$ radicals}

In a typical experiment, $3.5 \times 10^{-4} \mathrm{M} \mathrm{CV}$ solution was saturated with $\mathrm{N}_{2} \mathrm{O}$ gas prior to irradiation procedures and then gamma irradiated with absorbed doses up to 400 Gy The samples were then analyzed by UV-Visible spectrophotometer immediately after gamma -irradiation.

Under this condition all the $\mathrm{e}_{\mathrm{aq}}{ }^{-}$are converted into ${ }^{\circ} \mathrm{OH}$ radical and thus the concentration of ${ }^{\circ} \mathrm{OH}$ radical become higher in the gamma irradiated $\mathrm{CV}$ solution as shown by equation (9) [20].

$$
\mathrm{N}_{2} \mathrm{O}+\mathrm{e}_{\mathrm{aq}}^{-} \rightarrow \mathrm{OH}+{ }^{-} \mathrm{OH}+\mathrm{N}_{2} \quad k=9.1 \times 10^{9} \mathrm{M}^{-1} \mathrm{~s}^{-1}
$$

The degradation course of $\mathrm{CV}$ in dependence of the absorbed dose is shown in Figure 2. It can be seen that in the presence of excess amount of ${ }^{\circ} \mathrm{OH}$ radicals nearly $56 \%$ of $\mathrm{CV}$ dye was degraded at absorbed dose of $400 \mathrm{~Gy}$.

$\mathrm{D}_{0.5}, \mathrm{D}_{0.9}$ and $\mathrm{D}_{0.99}$ for degradation of $\mathrm{CV}$ when the sample solution contains high amount of ${ }^{\circ} \mathrm{OH}$ radicals are tabulated in table 1 . Which shows that $50 \%$, $90 \%$ and $99 \%$ of $\mathrm{CV}$ dye degradation can be achieved at absorbed doses of 315 Gy, 1046 Gy and 2093 Gy, respectively.

Table 2 shows the variation of $\mathrm{G}$ values of $\mathrm{CV}$ at different absorbed doses. A continuous decreasing trend in G-values was observed from $0.53-0.36$ molecules $/ 100 \mathrm{eV}$ at absorbed doses from 100 - $400 \mathrm{~Gy}$. This decreasing trend in G-values might be due to the fact that as the absorbed dose increases the concentration of target pollutant $(\mathrm{CV})$ decreases and the concentration of byproducts increases which then competes with the CV molecule for reactive radical [21].

\subsection{Reaction of $\mathrm{CV}$ with $\cdot \mathrm{H}$ radicals}

To investigate the involvement of ${ }^{\circ} \mathrm{H}$ radicals in the degradation of $\mathrm{CV}$ dye. The dye sample solution was bubbled with $\mathrm{N}_{2} \mathrm{O}$ gas and spiked with $10^{-2}$ $\mathrm{M}$ of tert-BUOH. Under this condition $\mathrm{e}^{-}$and ${ }^{\circ} \mathrm{OH}$ radicals are scavenged by $\mathrm{N}_{2} \mathrm{O}$ gas and tert-BUOH according to equations (9) and (10), respectively [20]. $\mathrm{SO}$, only ${ }^{*} \mathrm{H}$ radicals are available for reaction with $\mathrm{CV}$ dye as it has very slow reaction with tert - BUOH indicated by equation (11) [17].

tert-BUOH $+{ }^{\cdot} \mathrm{OH} \rightarrow{ }^{\cdot} \mathrm{CH}_{2} \mathrm{C}\left(\mathrm{CH}_{3}\right)_{2} \mathrm{OH}+\mathrm{H}_{2} \mathrm{O} k=5.5 \times 10^{8} \mathrm{M}^{-1} \mathrm{~s}^{-1}$

tert $-\mathrm{BUOH}+{ }^{\circ} \mathrm{H} \rightarrow{ }^{\circ} \mathrm{CH}_{2} \mathrm{C}^{2}\left(\mathrm{CH}_{3}\right)_{2} \mathrm{OH}+\mathrm{H}_{2} k=9 \times 10^{4} \mathrm{M}^{-1} \mathrm{~s}^{-1}$

The radicals formed as a byproducts of tert $\mathrm{BuOH}$ reaction with ${ }^{\circ} \mathrm{OH}$ and $\cdot \mathrm{H}$ radicals are assumed to be inert [22].

The $\%$ degradation plot of $\mathrm{CV}$ when aqueous system contains only ${ }^{\circ} \mathrm{H}$ radicals is shown in Fig. 3. The figures shows that nearly $3 \%$ of $\mathrm{CV}$ molecules was degraded at absorbed dose $400 \mathrm{~Gy}$. Which also indicates very less involvement of ${ }^{\circ} \mathrm{H}$ radicals in the degradation of $\mathrm{CV}$ dye. The $\mathrm{D}_{5}, \mathrm{D}_{09}$ and $\mathrm{D}_{0.99}$ values for the degradation of $\mathrm{CV}$ dye by ${ }^{*} \mathrm{H}$ radicals were found to be 1386 Gy, 4605 Gy and 9210 Gy, respectively as given in table 1. Which are higher than the values when the aqueous system contains excessive amount of ${ }^{\circ} \mathrm{OH}$ radicals. The G-values for the aqueous system containing ${ }^{\circ} \mathrm{H}$ radicals (tert$\mathrm{BUOH} / \mathrm{N}_{2} \mathrm{O}$ ) are given in table 2 with absorbed doses from 100 to $400 \mathrm{~Gy}$. The G-values were found to be in the range of $0.07-0.13$ molecules $/ 100 \mathrm{eV}$ at absorbed doses from $100-400 \mathrm{~Gy}$. Which are lower as compared to the case when $\mathrm{CV}$ dye was degraded in oxidative environment probably due to lower reactivity of $\cdot \mathrm{H}$-radicals towards $\mathrm{CV}$ dye molecule.

\subsection{Reaction of $\mathrm{CV}$ with ${ }^{\circ} \mathrm{H}$ radicals and $\mathrm{e}^{-}$}

In this experiment, nitrogen saturated ${ }^{\text {aq }} \mathrm{V}$ solution $\left(3.5 \times 10^{-5} \mathrm{M}\right)$ containing tert- $\mathrm{BuOH}\left(1 \times 10^{-2} \mathrm{M}\right)$ as $\cdot \mathrm{OH}$ radical scavenger was gamma irradiated at different absorbed doses (100 - 400 Gy). In $\mathrm{N}_{2}$-saturated solution all the three reactive species i.e. ${ }^{\circ} \mathrm{OH}$ radicals, $\mathrm{e}_{\mathrm{ag}}-$ and ${ }^{\circ} \mathrm{H}$ radicals have equal chances of reaction with $\mathrm{CV}$ dye molecule [17]. However, tert-BUOH scavenges ${ }^{\circ} \mathrm{OH}$ radical as shown by equation (10) and thus mainly $83 \% \mathrm{e}_{\mathrm{aq}}^{-}($ $\mathrm{G}=2.6)$ and $18 \% \cdot \mathrm{H}$ atoms $(\mathrm{G}=0.5)$ are involved in the degradation process.

Fig. 4 shows \% degradation of $\mathrm{CV}$ dye versus absorbed dose. The results shows that $14.37 \%$ of CV dye was degraded at absorbed dose of $400 \mathrm{~Gy}$. The doses required for $50 \%, 90 \%$ and $99 \%$ removal of $\mathrm{CV}$ dye from aqueous solution containing ${ }^{\circ} \mathrm{H}$ radical and $\mathrm{e}_{\text {aq }}{ }^{-}$were calculated to be $990 \mathrm{~Gy}, 3289 \mathrm{~Gy}$ and 6578 Gy respectively and are given in table 1 . The removal efficiency presented in terms of G-values are given in table 2 which shows a decreasing trend from $0.07-0.13$ molecules / $100 \mathrm{eV}$ with the increase in the absorbed dose from 100 - $400 \mathrm{~Gy}$.

\subsection{Reaction of $\mathrm{CV}$ with ${ }^{\circ} \mathrm{OH}$ radicals and $\mathrm{O}_{2}{ }^{-}$}

A sample solution containing $3.5 \times 10^{-5} \mathrm{M}$ of $\mathrm{CV}^{2}$ dye was gamma irradiated in the presence of air, $\left(\mathrm{O}_{2}=1.25 \times 10^{-3} \mathrm{~mol} \mathrm{dm}^{-3}\right)$ with absorbed doses up to $400 \mathrm{~Gy}$ and then analyzed by UV - Visible spectrophotometer to measure the changes in the absorption spectra of CV dye.

In aerated media all the $\mathrm{e}_{\text {aq }}{ }^{-}$and ${ }^{\circ} \mathrm{H}$ are converted to peroxyl radicals and superoxide radicals as shown by equations (12) and (13)), respectively [19].

$$
\begin{array}{cc}
\cdot \mathrm{H}^{+} \mathrm{O}_{2} \rightarrow \mathrm{HO}_{2}^{\cdot} & k=2.1 \times 10^{10} \mathrm{M}^{-1} \mathrm{~S}^{-1} \\
\mathrm{e}_{\mathrm{aq}}^{-}+\mathrm{O}_{2} \rightarrow \mathrm{O}_{2}^{\cdot} & k=1.9 \times 10^{10} \mathrm{M}^{-1} \mathrm{~s}^{-1} \\
\mathrm{HO}_{2} \approx \mathrm{H}^{+}+\mathrm{O}_{2}^{-} & p \mathrm{~K}=4.8
\end{array}
$$

The plot showing \% degradation of $\mathrm{CV}$ dye at various absorbed doses is presented in Fig. 5. At absorbed dose of 400 Gy nearly $47 \%$ of CV dye was degraded. $\mathrm{D}_{0.5}, \mathrm{D}_{0.9}$ and $\mathrm{D}_{0.99}$ values for air - saturated aqueous solution of $\mathrm{CV}$ dye were calculated as $495 \mathrm{~Gy}, 1644 \mathrm{~Gy}$ and $3289 \mathrm{~Gy}$, respectively and are given in table 1 . Under this conditions the G-values were in the range of 0.35 0.31 molecules / $100 \mathrm{eV}$ at absorb doses from 100 - 400 Gy as shown in table 2 . 
3.5 Reaction of $\mathrm{CV}$ with ${ }^{\circ} \mathrm{OH}$ radicals, $\mathrm{e}_{\mathrm{ag}}{ }^{-}$and ${ }^{\circ} \mathrm{H}$ radicals

Aqueous solution of CV dye $\left(3.5 \times 10^{-5} \mathrm{M}^{\text {aq }}\right)$ was bubbled with $\mathrm{N}_{2}$-gas for 20 minutes and then was gamma irradiated for different absorbed doses. In $\mathrm{N}_{2}$ saturated solution, all the three primary reactive species i.e. ${ }^{\circ} \mathrm{OH}$ radicals, ${ }^{\circ} \mathrm{H}$ radicals and $\mathrm{e}_{\text {aq }}{ }^{-}$are playing their role in the degradation of $\mathrm{CV}$ dye [23]. At absorbed dose of $400 \mathrm{~Gy}, 36 \%$ degradation of $\mathrm{CV}$ dye was observed as shown in Fig. 6. Under these conditions $46 \%{ }^{\circ} \mathrm{OH}(\mathrm{G}=2.7), 44 \% \mathrm{e}_{\text {aq }}^{-}(\mathrm{G}=2.6)$ and 8 $\% \cdot \mathrm{H}(\mathrm{G}=0.5)$ are operative for degradation of $\mathrm{CV}$ dye. By using equation (2), (3) and (4) $\mathrm{D}_{0.5}, \mathrm{D}_{0.9}$ and $\mathrm{D}_{0.99}$ values for the removal of $\mathrm{N}_{2}$ saturated aqueous $\mathrm{CV}$ dye solution were calculated as $462 \mathrm{~Gy}, 1535 \mathrm{~Gy}$ and $3070 \mathrm{~Gy}$, respectively as given in table 1 . The $\mathrm{G}$-values for the removal of $\mathrm{CV}$ dye from aqueous solution was calculated in the range of $0.17-0.22$ molecules / $100 \mathrm{eV}$ with absorbed doses from 100 - 400 Gy. The removal efficiency (G-value) was decreased from 0.17 to 0.14 molecules / $100 \mathrm{eV}$ when the absorbed dose was increased from 100 to $400 \mathrm{~Gy}$. Which is in accordance with previous reported results for destruction of methyl tert-butyl ether in water in presence of chloroform [21].

3.6 Reaction of $\mathrm{CV}$ with $\mathrm{e}_{\mathrm{aq}}$ -

The role of $\mathrm{e}^{-}$in the degradation of $\mathrm{CV}$ dye was examined by purging the sample solution with $\mathrm{N}_{2}$ gas for 20 minutes. In this experiment the $\mathrm{N}_{2}$ saturated CV dye solution was spiked with $10^{-2} \mathrm{M}$ iso-propanol solution. isopropanol scavenges ${ }^{\circ} \mathrm{OH}$ radicals and ${ }^{\circ} \mathrm{H}$ atoms by a very fast reaction as shown in the equation (15) and (16), respectively [17]. So, under these conditions mainly $\mathrm{e}_{\text {aq }}{ }^{-}$are involved in the degradation of $\mathrm{CV}$ dye.

$$
\begin{aligned}
& \cdot \mathrm{OH}+\left(\mathrm{CH}_{3}\right)_{2} \mathrm{CHOH} \rightarrow \mathrm{H}_{2} \mathrm{O}+\left(\mathrm{CH}_{3}\right)_{2} \mathrm{C} \cdot \mathrm{OH} k=6.3 \times 10^{8} \mathrm{M}^{-1} \mathrm{~s}^{-1} \\
& \cdot \mathrm{H}+\left(\mathrm{CH}_{3}\right)_{2} \mathrm{CHOH} \rightarrow \mathrm{H}_{2}+\left(\mathrm{CH}_{3}\right)_{2} \mathrm{C} \cdot \mathrm{OH} k=1.6 \times 10^{9} \mathrm{M}^{-1} \mathrm{~s}^{-1}
\end{aligned}
$$

Fig. 7 shows \% degradation of $\mathrm{CV}$ dye solution at different absorbed doses. From this Fig. it can be seen that $10.76 \%$ degradation of CV dye can be achieved at absorbed dose of $400 \mathrm{~Gy}$. Under these conditions the doses required for $50 \%\left(\mathrm{D}_{0.5}\right), 90 \%\left(\mathrm{D}_{0.9}\right)$ and $99 \%\left(\mathrm{D}_{0.99}\right)$ degradation of $\mathrm{CV}$ dye are $231 \mathrm{~Gy}$, $767 \mathrm{~Gy}$ and $1535 \mathrm{~Gy}$, respectively as given in table 1 . Table 2 shows variations in G-values for the removal of $\mathrm{N}_{2}$-saturated $\mathrm{CV}$ dye from aqueous solution spiked with $10^{-2} \mathrm{M}$ iso-propanol. The G-values obtained under reductive environment ( $\mathrm{e}_{\text {aq }}{ }^{-}$reactions) were lower than the oxidative environment ( $\textrm{OH}$ radical reactions) which shows that removal efficiency of $\mathrm{e}^{-}$for removing $\mathrm{CV}$ dye from aqueous solution is not as effective as ${ }^{\circ} \mathrm{OH}$ radical.

Fig. 8 shows comparative removal of $\mathrm{CV}$ dye from aqueous solution under different reaction conditions. The decay constant $(k$ for the removal of $\mathrm{CV}$ dye from aqueous solution was found in the order of $\mathrm{N}_{2} \mathrm{O}>\mathrm{Air}>\mathrm{N}_{2}>$ iso - PrOH $/ \mathrm{N}_{2}>$ tert $-\mathrm{BUOH} / \mathrm{N}_{2}>$ tert $-\mathrm{BUOH} / \mathrm{N}_{2} \mathrm{O}$. The highest $\%$ degradation of $\mathrm{CV}$ dye in $\mathrm{N}_{2} \mathrm{O}$ saturated media is due to high concentration of ${ }^{\circ} \mathrm{OH}$ radicals availability for reaction with $\mathrm{CV}$ dye.

\section{Degradation pathway of $\mathrm{CV}$ dye}

Identification of main byproducts of $\mathrm{CV}$ dye was done by using HPLC-Ms analytical tool. $10 \mathrm{mg} \mathrm{L}^{-1}$ of $\mathrm{CV}$ dye at natural $\mathrm{pH}(\mathrm{pH}=6.4)$ was introduced into HPLC-MS. Five degradation byproducts were originated; N-methyl aniline, $\mathrm{N}, \mathrm{N}$-dimethyl aniline, 4-methyl-N,N-dimethylaniline, 4-dimethylamino phenol, and 4-dimethylamino benzoic acid. Fan and co-workers [24] also investigated similar byproducts during degradation of $\mathrm{CV}$ dye by Fenton processes. The formation of these by-products suggests that during degradation of $\mathrm{CV}$ dye, the main specie involve in the degradation process is ${ }^{\circ} \mathrm{OH}$ radical. The evaluated degradation products are arranged to establish a degradation pathway (as given in scheme 1).

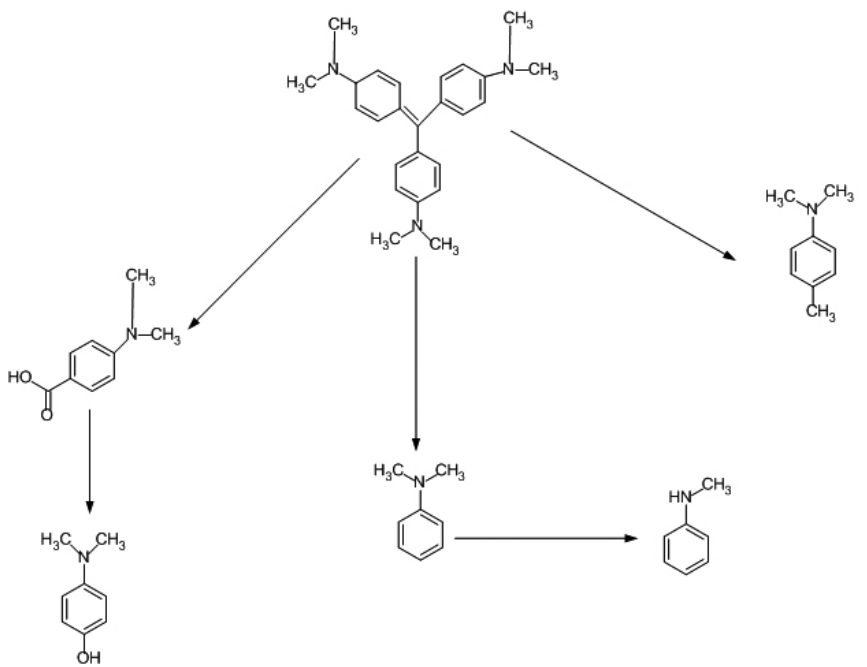

Scheme 1: Proposed degradation pathway of CV by gamma irradiation.

\section{CONCLUSIONS}

The removal of $\mathrm{CV}$ dye from aqueous solution as a function of absorbed dose has been investigated under various experimental conditions. The highest removal efficiency was observed when the $\mathrm{CV}$ dye solution is saturated with $\mathrm{N}_{2} \mathrm{O}$ gas and then gamma-irradiated. All the three main reactive species i.e. ${ }^{\circ} \mathrm{OH}$ radicals, $\mathrm{e}_{\mathrm{aq}}{ }^{-}$and ${ }^{\circ} \mathrm{H}$ radicals are playing their role in the degradation of $\mathrm{CV}$ dye. However, ${ }^{\text {ag }} \mathrm{OH}$ radicals were observed to be the dominant species in the removal of $\mathrm{CV}$ dye. The ${ }^{\circ} \mathrm{OH}$-radical scavengers like tert-BUOH and iso-PrOH restrained the degradation process of $\mathrm{CV}$ dye.

\section{ACKNOWLEDGEMENTS}

Authors are highly thankful to Higher Education Commission (HEC) of Pakistan and Director NCE Physical Chemistry, University of Peshawar ,Pakistan for providing research facilities.

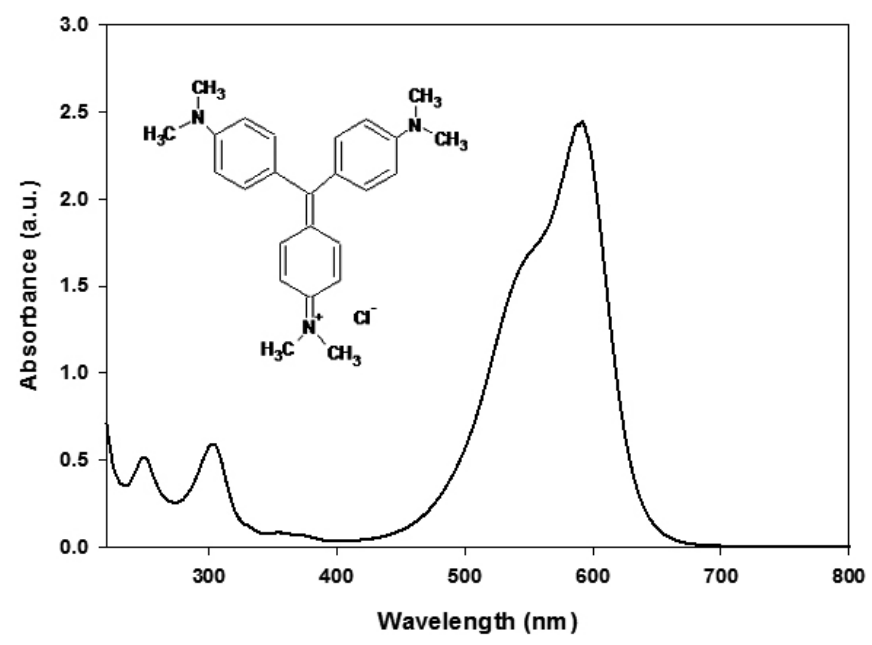

Fig.1 UV absorption spectra of CV dye aqueous solution, inset shows molecular structure of CV dye. 
J. Chil. Chem. Soc., 62, No 1 (2017)

Table. $1 \mathrm{D}_{0.5}, \mathrm{D}_{0.9}$ and $\mathrm{D}_{0.99}$ values for the removal of $\mathrm{CV}$ dye from aqueous solution under different experimental conditions.

\begin{tabular}{|c|c|c|c|c|c|c|c|}
\hline $\begin{array}{c}\text { Absorbed } \\
\text { dose }(\mathbf{G y})\end{array}$ & & Air - saturated & $\mathbf{N}_{\mathbf{2}}-$ saturated & $\mathbf{N}_{\mathbf{2}} \mathbf{O}$ - saturated & $\begin{array}{c}\text { iso-PrOH } \\
/ \mathbf{N}_{2}\end{array}$ & $\begin{array}{c}\text { tert }-\mathrm{BUOH} \\
/ \mathbf{N}_{2}\end{array}$ & $\begin{array}{c}\text { tert-BUOH / } \\
\mathbf{N}_{\mathbf{2}} \mathbf{O}\end{array}$ \\
\hline \multirow{3}{*}{$\mathbf{0}-\mathbf{4 0 0}$} & $\mathbf{D}_{\mathbf{0 . 5}}(\mathbf{G y})$ & 495 & 462 & 315 & 231 & 990 & 1386 \\
\cline { 2 - 9 } & $\mathbf{D}_{\mathbf{0 . 9}}(\mathbf{G y})$ & 1644 & 1535 & 1046 & 767 & 3289 & 4605 \\
\cline { 2 - 9 } & $\mathbf{D}_{0.99}(\mathbf{G y})$ & 3289 & 3070 & 2093 & 1535 & 6578 & 9210 \\
\hline
\end{tabular}

Table. $2 \mathrm{G}$-values for the removal of $\mathrm{CV}$ dye from aqueous solution under different experimental conditions.

\begin{tabular}{|c|c|c|c|c|c|c|}
\hline \multirow{2}{*}{$\begin{array}{l}\text { Absorbed dose } \\
\text { (Gy) }\end{array}$} & \multicolumn{6}{|c|}{ G -Value (molecules/ $100 \mathrm{eV}$ ) } \\
\hline & Air - saturated & $\mathrm{N}_{2}$-saturated & $\mathrm{N}_{2} \mathrm{O}$-saturated & iso-PrOH/ $\mathrm{N}_{2}$ & tert-BuOH/ $\mathrm{N}_{2}$ & tert-BuOH/ $\mathrm{N}_{2} \mathrm{O}$ \\
\hline 0 & - & - & - & - & - & - \\
\hline 100 & 0.35 & 0.17 & 0.53 & 0.09 & 0.07 & 0.07 \\
\hline 200 & 0.39 & 0.15 & 0.44 & 0.12 & 0.11 & 0.11 \\
\hline 400 & 0.31 & 0.14 & 0.36 & 0.08 & 0.13 & 0.13 \\
\hline
\end{tabular}

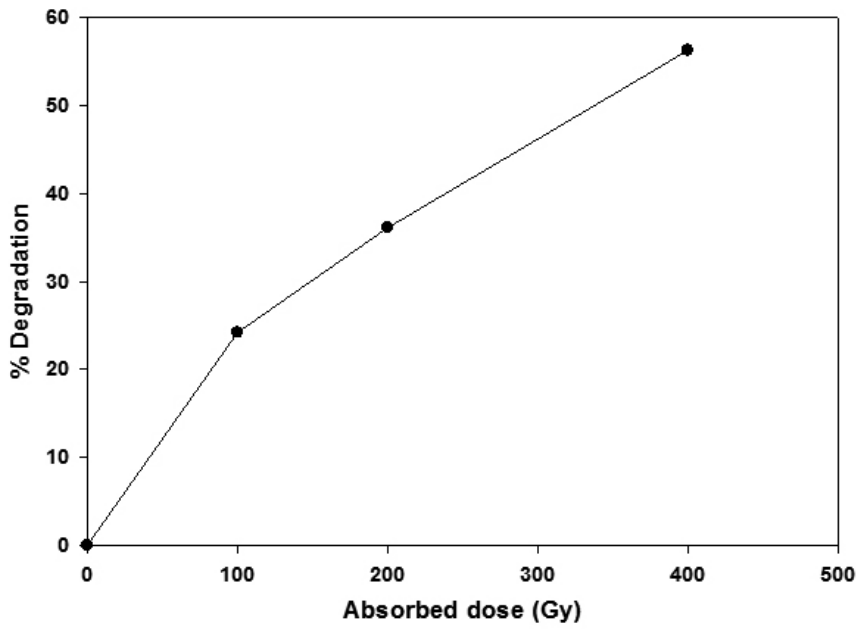

Fig. 2 Degradation of $\mathrm{N}_{2} \mathrm{O}$ saturated aqueous solution of $\mathrm{CV}$ dye.

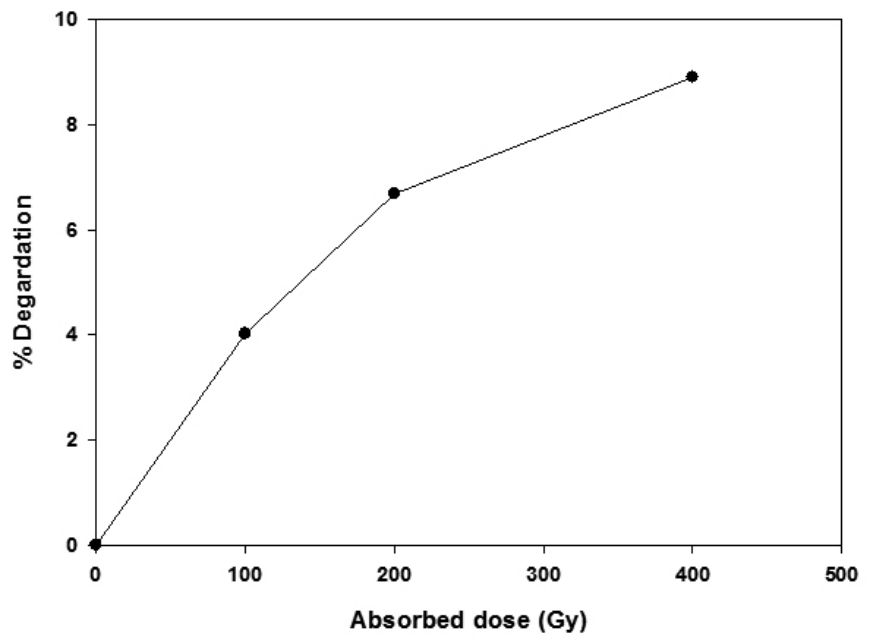

Fig.3 Degradation of $\mathrm{N}_{2} \mathrm{O}$ saturated $\mathrm{CV}$ dye containing $10^{-2} \mathrm{M}$ tertBUOH.

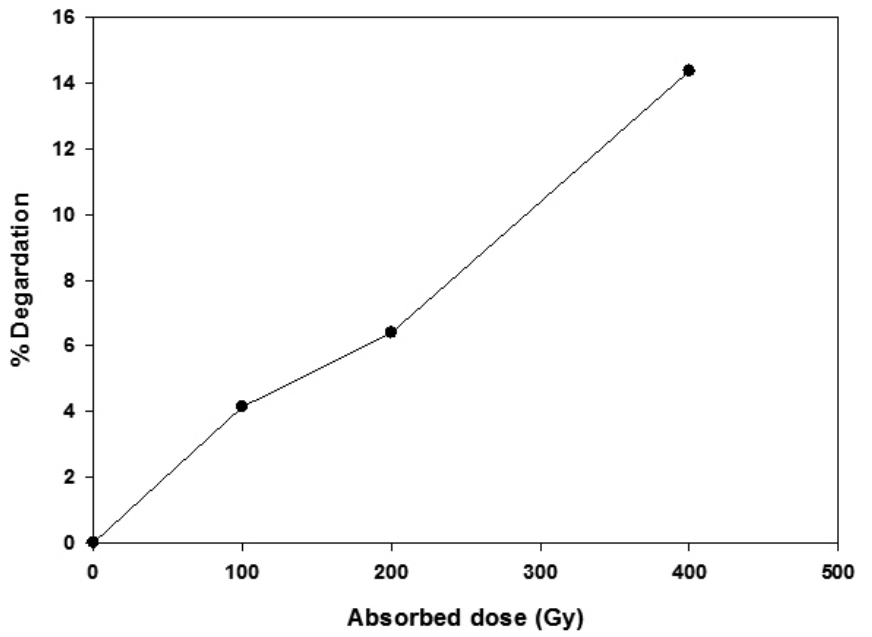

Fig. 4 Degradation of $\mathrm{N}_{2}$ saturated CV dye containing $10^{-2} \mathrm{M}$ tert-BUOH

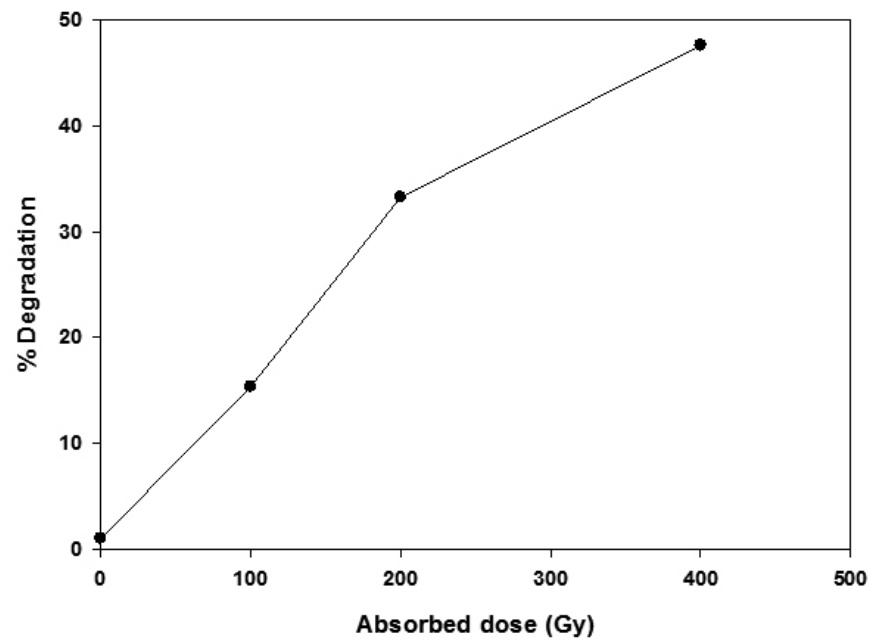

Fig. 5 Degradation of air- saturated CV dye solution 


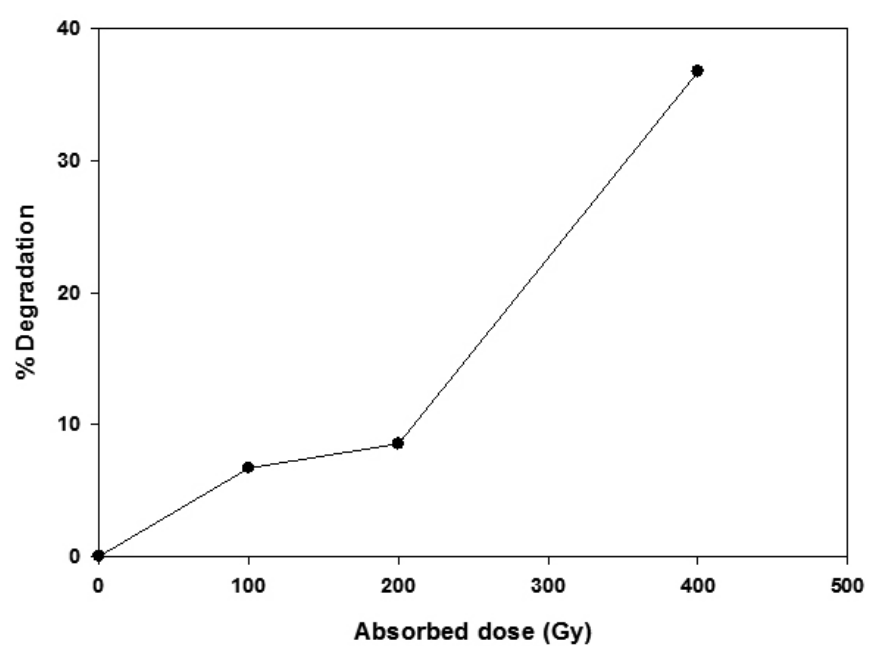

Fig. 6 Degradation of $\mathrm{N}_{2}$ - saturated $\mathrm{CV}$ dye solution

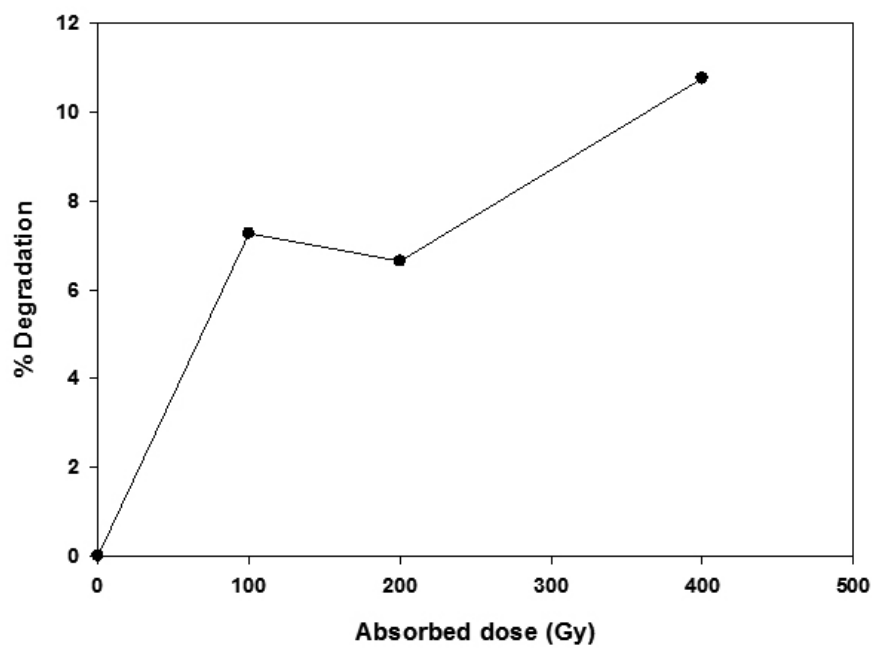

Fig. 7 Degradation of $\mathrm{N}_{2}$ - saturated $\mathrm{CV}$ dye solution spiked with $10^{-2} \mathrm{M}$ iso-PrOH

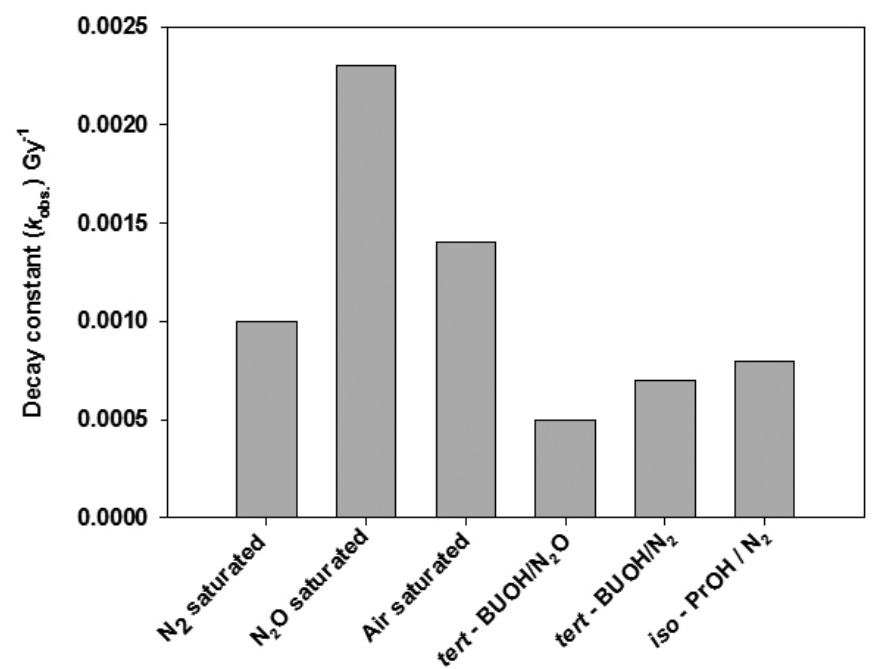

Fig. 8 Comparative removal of $\mathrm{CV}$ dye from aqueous solution under various experimental conditions

\section{REFERENCES}

1. M Lučić, N Milosavljević, M Radetić, Z Šaponjić, M Radoičić, MK Krušić: The potential application of TiO 2/hydrogel nanocomposite for removal of various textile azo dyes. Separation and Purification Technology 2014, 122:206-216.

2. H Olvera-Vargas, N Oturan, C Aravindakumar, MS Paul, VK Sharma, MA Oturan: Electro-oxidation of the dye azure B: kinetics, mechanism, and by-products. Environmental Science and Pollution Research 2014, 21:8379-8386.

3. M Tichonovas, E Krugly, V Racys, R Hippler, V Kauneliene, I Stasiulaitiene, D Martuzevicius: Degradation of various textile dyes as wastewater pollutants under dielectric barrier discharge plasma treatment. Chemical Engineering Journal 2013, 229:9-19.

4. F Zhang, C Feng, W Li, J Cui: Indirect electrochemical oxidation of dye wastewater containing Acid Orange 7 using Ti/RuO2-Pt electrode. Int. J. Electrochem. Sci. 2014, 9:943-954.

5. A Azarkohan, F Shemirani, M Alvand: Fast analysis of water samples for trace amount of crystal violet dye based on solid phase extraction using nanoporous SBA-3 prior to determination by fiber optic-linear array detection spectrophotometry. Journal of Chemistry 2013, 2013.

6. S Mondal: Methods of dye removal from dye house effluentâe"an overview. Environmental Engineering Science 2008, 25:383-396.

7. F Al-Momani, E Touraud, J Degorce-Dumas, J Roussy, O Thomas: Biodegradability enhancement of textile dyes and textile wastewater by VUV photolysis. Journal of photochemistry and Photobiology A: Chemistry 2002, 153:191-197.

8. DR Manenti, PA Soares, TnF Silva, AN MÃ $\tilde{3}^{3}$ enes, FR EspinozaQuiÃ \pm ones, Rn Bergamasco, RA Boaventura, VJ Vilar: Performance evaluation of different solar advanced oxidation processes applied to the treatment of a real textile dyeing wastewater. Environmental Science and Pollution Research 2014, 22:833-845.

9. Y-H Huang, Y-F Huang, C-i Huang, C-Y Chen: Efficient decolorization of azo dye Reactive Black B involving aromatic fragment degradation in buffered Co 2+/PMS oxidative processes with a ppb level dosage of Co 2+-catalyst. Journal of hazardous materials 2009, 170:1110-1118.

10. L Abdou, O Hakeim, M Mahmoud, A El-Naggar: Comparative study between the efficiency of electron beam and gamma irradiation for treatment of dye solutions. Chemical Engineering Journal 2011, 168:752758.

11. H Fricke, EJ Hart: Chemical dosimetry. Radiation dosimetry 1966, 2:167239

12. X Jun, W Jianlong: Radiolysis of pentachlorophenol (PCP) in aqueous solution by gamma radiation. Journal of Environmental Sciences 2008, 20:1153-1157.

13. M Ismail, HM Khan, M Sayed, WJ Cooper: Advanced oxidation for the treatment of chlorpyrifos in aqueous solution. Chemosphere 2013, 93:645651.

14. W Sun, L Chen, J Tian, J Wang, S He: Degradation of a monoazo dye Alizarin Yellow GG in aqueous solutions by gamma irradiation: decolorization and biodegradability enhancement. Radiation Physics and Chemistry 2013, 83:86-89.

15. JWT Spinks, RJ Woods: An introduction to radiation chemistry. 1990

16. A Bhasikuttan, A Sapre, L Shastri: Oxidation of crystal violet and malachite green in aqueous solutionsâ€"a kinetic spectrophotometric study. Journal of photochemistry and Photobiology A: Chemistry 1995, 90:177-182.

17. GV Buxton, CL Greenstock, WP Helman, AB Ross: Critical review of rate constants for reactions of hydrated electrons, hydrogen atoms and hydroxyl radicals $\left(\hat{a}<\ldots\right.$. OH/âk... Oân ${ }^{\wedge}$ in aqueous solution. Journal of physical and chemical reference data 1988, 17:513-886.

18. Z Guo, F Zhou, Y Zhao, C Zhang, F Liu, C Bao, M Lin: Gamma irradiationinduced sulfadiazine degradation and its removal mechanisms. Chemical Engineering Journal 2012, 191:256-262.

19. Y Peng, S He, J Wang, W Gong: Comparison of different chlorophenols degradation in aqueous solutions by gamma irradiation under reducing conditions. Radiation Physics and Chemistry 2012, 81:1629-1633.

20. NS Shah, JA Khan, S Nawaz, HM Khan: Role of aqueous electron and hydroxyl radical in the removal of endosulfan from aqueous solution using gamma irradiation. Journal of hazardous materials 2014, 278:40-48.

21. AA Basfar, HM Khan, AA Al-Shahrani, WJ Cooper: Radiation induced decomposition of methyl tert-butyl ether in water in presence of chloroform: kinetic modelling. Water research 2005, 39:2085-2095. 
22. M S Ã $j n c h e z-P o l o, J ~ L \tilde{A}^{3}$ pez-PeÃ \pm alver, G Prados-Joya, M Ferro-GarcÃa, J Rivera-Utrilla: Gamma irradiation of pharmaceutical compounds, nitroimidazoles, as a new alternative for water treatment. Water research 2009, 43:4028-4036.

23. N Getoff: Radiation-induced degradation of water pollutantsâ€"state of the art. Radiation Physics and Chemistry 1996, 47:581-593.

24. H-J Fan, S-T Huang, W-H Chung, J-L Jan, W-Y Lin, C-C Chen: Degradation pathways of crystal violet by Fenton and Fenton-like systems: condition optimization and intermediate separation and identification. Journal of hazardous materials 2009, 171:1032-1044. 